\title{
ACCURACY OF REGISTERED CAUSES OF NEONATAL DEATHS IN 1958
}

\author{
JEAN FEDRICK AND N. R. BUTLER \\ Unit of Clinical Epidemiology, Department of the Regius Professor of Medicine, University of Oxford and \\ Department of Child Health, University of Bristol
}

The ensuing analyses have been compiled for two main reasons. First, from an epidemiological standpoint it is important to know how meaningful are the statistics published by the Registrar General. Secondly, before the Ninth Revision of the International Classification of Diseases is finalized it might be of advantage to ascertain the shortcomings of the Seventh and Eighth Revisions. To this end it is proposed to carry out two studies.

The first, presented here, examines the coding of cause of death given by the General Register Office (now the Office of Population Censuses and Surveys) to neonatal deaths in the 1958 British Perinatal Mortality Survey using the Seventh Revision, and compares this with the causes of death as ascertained by necropsy. The second will compare the coding given by the GRO (using the Eighth Revision) to perinatal deaths in the Oxford region for the years 1968 to 1970 with that considered ideal from the clinical and postmortem reports collected by the Oxford Record Linkage Study.

\section{Material ANd Methods}

One of the most valuable results of the 1958 British Perinatal Mortality Survey (BPMS) was a detailed study of $95 \%$ of all stillbirths and neonatal deaths occurring in England, Scotland, and Wales during the three-month period March, April, and May 1958 (Butler and Bonham, 1963; Butler and Alberman, 1969). Detailed necropsies were carried out on $68 \%$, and in the vast majority of cases the lung histology was examined by a team under the chairmanship of Dr. A. E. Claireaux for consistency of diagnosis of pulmonary lesions such as massive pulmonary haemorrhage, pulmonary infection, and hyaline membranes.

At this time the cause of stillbirth was not required to be registered in England and Wales. We have therefore considered only the neonatal deaths (i.e., deaths before 28 days).

The registered causes of death were obtained from the Medical Officers of Health concerned and the code awarded was obtained from the GROs for
England and Wales and for Scotland. The purpose of the analysis is primarily to ascertain to what extent the registered causes of death correspond with the causes of death as ascertained by perinatal mortality survey necropsies, and secondly to determine how a system of multiple codings might improve the situation.

\section{RESUlts}

Malformations of the Central Nervous System

The malformations of the central nervous system would be expected to be delineated on the death certificate more accurately than other causes of death, being (apart from a very small proportion of cases of hydrocephalus) grossly apparent to the naked eye.

\section{ANENCEPHALUS}

Of the 36 neonatal deaths ascertained by the BPMS as anencephalic, 32 were described as such and given the appropriate code (750X) on the death certificate. No amount of multicoding could have increased the accuracy here, one case being described on the death certificate as spina bifida with generalized congenital malformations, two as multiple congenital abnormalities, and one as microcephaly!

\section{SPINA BIFIDA}

Spina bifida is taken here to include cases of meningocele, myelocele, encephalocele, etc., in the absence of anencephalus. It is the custom for epidemiologists to assume that all cases are given the code 751X regardless of whether hydrocephalus was present. It can be seen, however, from Table 1A that only $52 \%$ of the neonatal deaths with spina bifida ascertained by the BPMS were given the code $751 \mathrm{X}$ by the GRO. However, inspection of the death certificates would reveal that actually 108 of the 120 cases were described as having spina bifida, and only in 2 cases was there no mention of any congenital malformation at all (Table 1B). 
TABLE IA

MALFORMATIONS OF THE CENTRAL NERVOUS SYSTEM

\begin{tabular}{|c|c|c|c|c|c|}
\hline \multirow{2}{*}{$\begin{array}{l}\text { Registered Cause } \\
\text { of Death }\end{array}$} & \multicolumn{4}{|c|}{ Observed Cause of Death } & \multirow[b]{2}{*}{ Total } \\
\hline & $\begin{array}{l}\text { Anen- } \\
\text { cephalus }\end{array}$ & $\begin{array}{l}\text { Spina } \\
\text { Bifida }\end{array}$ & $\begin{array}{l}\text { Hydro- } \\
\text { cephalus }\end{array}$ & Other & \\
\hline 750X Monstrosity & 32 & 2 & $\mathbf{0}$ & 3 & 37 \\
\hline $\begin{array}{l}751 X \text { Spina bifida } \\
\text { and meningocele }\end{array}$ & 1 & 62 & $\mathbf{0}$ & 2 & 65 \\
\hline $\begin{array}{l}\text { 752X Congenital } \\
\text { hydrocephalus }\end{array}$ & $\mathbf{0}$ & 30 & 8 & 7 & 45 \\
\hline $\begin{array}{l}\text { Other congenital } \\
\text { malformation }\end{array}$ & 3 & 13 & 2 & 242 & 260 \\
\hline $\begin{array}{l}\text { No congenital } \\
\text { malformation }\end{array}$ & $\mathbf{0}$ & 13 & 4 & 1,232 & 1,249 \\
\hline Total & 36 & 120 & 14 & 1,486 & 1,656 \\
\hline$\%$ correct & $89 \%$ & $52 \%$ & $57 \%$ & - & - \\
\hline
\end{tabular}

\section{HYDROCEPHALUS}

Of the 14 cases with neonatal hydrocephalus, with no mention of spina bifida in the BPMS, only 8 were given the correct code, $752 \mathrm{X}$. The mythical perfect coder, on returning to the death certificates, would have found that two cases, described as 'acute hydrocephalus', had apparently been given the code 010X (tuberculosis of the meninges and central nervous system). For the other 4 cases, no mention was made of hydrocephalus. Hence the maximum possible proportion of cases coded as hydrocephalus would have been $71 \%$.

\section{Other Major Malformations}

We now exclude all infants with CNS malformations and consider the accuracy of reporting of other
TABLE IB

CODES EXPECTED FROM EXAMINATION OF DEATH CERTIFICATES BY MULTIPLE CAUSE CODER

\begin{tabular}{l|ccc}
\hline \multirow{2}{*}{$\begin{array}{c}\text { Registered Cause } \\
\text { of Death }\end{array}$} & \multicolumn{3}{|c}{ Observed Cause of Death } \\
\cline { 2 - 4 } & Anencephalus & Spina Bifida & Hydrocephalus \\
\hline $750 X$ Monstrosity & 32 & 2 & 0 \\
751 X Spina bifida & 1 & 108 & 0 \\
$752 X$ Hydrocephalus & 0 & 3 & 10 \\
Other CM & 3 & 5 & 2 \\
No CM & 0 & 2 & 2 \\
\hline Total & 36 & 120 & 14 \\
\hline$\%$ correct & $89 \%$ & $90 \%$ & $71 \%$ \\
\hline
\end{tabular}

major lesions (Tables IIA and IIB). Here we have used an arbitrary 'hierarchical order' starting by considering all cases determined by the BPMS as having exomphalos. These have then been excluded and all cases with oesophogeal atresia (with or without tracheo-oesophageal fistula) have been studied. These are then excluded and cases of diaphragmatic hernia considered .... and so on.

\section{ExomphaLOS}

As with CNS malformations, one might expect à high standard of reporting on the death certificates, the lesion being grossly apparent. Only 9 of the 14 cases with exomphalos were so coded, however, although exomphalos was delineated on the death certificates in a further three cases (Tables IIA and IIB).

TABLE IIA

NEONATAL DEATHS WITH OTHER MAJOR CONGENITAL MALFORMATIONS (the categories being mutually exclusive and cases with CNS malformations having been excluded)

\begin{tabular}{|c|c|c|c|c|c|c|c|c|}
\hline \multirow{2}{*}{$\begin{array}{l}\text { Registered Cause } \\
\text { of Death }\end{array}$} & \multicolumn{5}{|c|}{ Observed Cause of Death } & \multirow{2}{*}{$\begin{array}{l}\text { Other } \\
\text { CM }\end{array}$} & \multirow{2}{*}{$\stackrel{\text { No }}{\mathbf{C M}}$} & \multirow[b]{2}{*}{ Total } \\
\hline & Exomphalos & $\begin{array}{c}\text { Oesophageal } \\
\text { Atresia }\end{array}$ & $\begin{array}{c}\text { Diaphagmatic } \\
\text { Hernia }\end{array}$ & $\begin{array}{c}\text { Congenital } \\
\text { Heart Disease }\end{array}$ & Renal & & & \\
\hline $\left.\begin{array}{l}560 \cdot 2 \\
561 \cdot 2\end{array}\right\}$ & 9 & - & - & - & - & - & - & 9 \\
\hline $756 \cdot 2$ & - & 23 & - & 2 & - & 11 & 3 & 39 \\
\hline $\left.\begin{array}{l}560.4 \\
759.0\end{array}\right\}$ & - & - & 11 & - & 1 & 1 & 1 & 14 \\
\hline $754 \cdot 0-754 \cdot 7$ & - & 1 & - & 91 & - & 2 & 11 & 105 \\
\hline $\left.\begin{array}{l}757 \cdot 1 \\
757 \cdot 3\end{array}\right\}$ & - & - & - & 2 & 6 & 8 & 1 & 17 \\
\hline $\begin{array}{l}\text { Other CM } \\
\text { No CM }\end{array}$ & $\begin{array}{l}1 \\
4\end{array}$ & $\begin{array}{l}2 \\
5\end{array}$ & $\begin{array}{r}3 \\
12\end{array}$ & $\begin{array}{r}9 \\
45\end{array}$ & $\begin{array}{r}2 \\
10\end{array}$ & $\begin{array}{l}43 \\
38\end{array}$ & $\begin{array}{r}4 \\
1,118\end{array}$ & $\begin{array}{r}64 \\
1,232\end{array}$ \\
\hline Total & 14 & 31 & 26 & 149 & 19 & 103 & 1,138 & 1,400 \\
\hline$\%$ correct ICD & $64 \%$ & $74 \%$ & $42 \%$ & $61 \%$ & $32 \%$ & & & \\
\hline
\end{tabular}




\section{Oesophageal Atresia}

The coding for the 31 neonatal deaths with this lesion was correct for $74 \%$, and an examination of the death certificates revealed only one case in which the lesion had been described but not coded. In five cases no malformation was noted on the death certificate.

\section{Diaphragmatic HeRnia}

It can be seen from Tables IIA and IIB how poorly reported this fairly common malformation appears to be. Even multiple coding would have managed to place only $58 \%$ of the cases in the correct category.

\section{Congenital Heart Disease (CHD)}

Considering the frequent difficulty of diagnosis, it is surprising how accurate the descriptions on the death certificates were. In all, some $61 \%$ of the 149 cases ascertained by the BPMS were coded as CHD by the General Register Office, and a multicode system would have increased this to $72 \%$.

\section{Major Renal Malformations}

Here we consider the 19 neonatal deaths with either bilateral renal agenesis or large polycystic kidneys (in the absence of any of the major malformations already described). Here the standard of reporting seems very poor. Over half the cases were coded as having no major malformation, and even a system of multicoding would improve the situation only slightly.

Thus the coding of the major malformations, even given a perfect coding system, could not have achieved an accuracy greater than $90 \%$ for even the easily recognized malformations such as anence- phalus, spina bifida, and exomphalos. For internal malformations such as diaphragmatic hernia and major renal defects the coding could have been correct only in less than $60 \%$ of cases, although recognition of congenital heart disease appears to have been more accurate.

From the analyses of other causes of neonatal death which follow, all cases of major congenital malformations have been excluded.

\section{RHESUS ISOIMMUNIZATION}

In all, 78 of the 88 deaths judged to have been a result of Rhesus incompatibility were coded as such (Table III). In 6 of the 10 cases not so coded this

TABLE III

RHESUS ISOIMMUNIZATION

\begin{tabular}{l|cc|c}
\hline $\begin{array}{c}\text { Registered Cause } \\
\text { of Death }\end{array}$ & \multicolumn{2}{|c|}{ Observed Cause of Death } & Total \\
\cline { 2 - 3 } & Rhesus & Remainder & \\
\hline $770 \cdot 0-770 \cdot 7$ & 78 & 10 & 88 \\
Remainder & 10 & 1,552 & 1,562 \\
\hline Total & 88 & 1,562 & 1,650 \\
\hline
\end{tabular}

(ICD correct in $89 \%$ of cases)

condition was noted on the death certificate, and hence a system of multicoding would increase the proportion of cases correctly coded to $95 \%$.

\section{Cerebral Birth Injury}

The codes $760.0,760.5$ were supposed to be employed in the presence of intracranial or spinal injury at birth and hence should include all cases

TABLE IIB

CODES EXPECTED FROM EXAMINATION OF DEATH CERTIFICATES BY MULTIPLE CAUSE CODER

\begin{tabular}{|c|c|c|c|c|c|}
\hline \multirow[b]{2}{*}{ Registered Cause of Death } & \multicolumn{5}{|c|}{ Observed Cause of Death } \\
\hline & Exomphalos & $\begin{array}{c}\text { Oesophageal } \\
\text { Atresia }\end{array}$ & $\begin{array}{c}\text { Diaphragmatic } \\
\text { Hernia }\end{array}$ & $\begin{array}{c}\text { Congenital } \\
\text { Heart Disease }\end{array}$ & Renal \\
\hline $\left.\begin{array}{l}560 \cdot 2 \\
561 \cdot 2\end{array}\right\}$ & & - & - & - & - \\
\hline $756 \cdot 2$ & - & 24 & 一 & 1 & - \\
\hline $\left.\begin{array}{l}560.4 \\
759.0\end{array}\right\}$ & - & - & 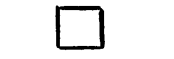 & - & - \\
\hline $754 \cdot 0-754 \cdot 7$ & - & - & - & 107 & - \\
\hline $\left.\begin{array}{l}757.1 \\
757 \cdot 3\end{array}\right\}$ & - & - & - & 1 & 11 \\
\hline $\begin{array}{l}\text { Other CM } \\
\text { No CM }\end{array}$ & 1 & $\begin{array}{l}2 \\
5\end{array}$ & $\begin{array}{l}3 \\
8\end{array}$ & $\begin{array}{r}4 \\
36 \\
\end{array}$ & $\overline{8}$ \\
\hline Total & 14 & 31 & 26 & 149 & 19 \\
\hline$\%$ correct & $86 \%$ & $77 \%$ & $58 \%$ & $72 \%$ & $58 \%$ \\
\hline
\end{tabular}


with cerebral birth trauma. In fact, of the 173 cases known to have been cases of cerebral birth trauma, some $70 \%$ were coded in this way (Table IV). An

TABLE IV

INTRACRANIAL HAEMORRHAGE

\begin{tabular}{l|r|r|r|r}
\hline \multirow{2}{*}{$\begin{array}{l}\text { Registered Cause } \\
\text { of Death }\end{array}$} & \multicolumn{2}{|c|}{ Observed Cause of Death } & Total \\
\cline { 2 - 3 } \cline { 5 - 5 } & CBT & IVH & Remainder & \\
\hline $760 \cdot 0$ & 106 & 21 & 51 & 178 \\
760.5 & 16 & 16 & 32 & 64 \\
Remainder & 51 & 82 & 1,275 & 1,408 \\
\hline Total & 173 & 119 & 1,358 & 1,650 \\
\hline
\end{tabular}

CBT $=$ cerebral birth trauma

IVH $=$ intraventricular haemorrhage

examination of the death certificates produced only nine further cases which a multiple coding system would be able to add to this classification.

\section{INTRAVENTRICULAR HAEMORRHAGE}

This lesion has been shown to be primarily associated with immaturity and not to be the result of birth injury (Fedrick and Butler, 1970). Nevertheless, some $30 \%$ of the cases were coded as 760.0 and 760.5 , this being the code into which cases described as cerebral haemorrhage were put by the ICD classification.

\section{Pulmonary Lesions}

Here we have excluded cases ascertained by the BPMS as being due to Rhesus isoimmunization, cerebral birth trauma or intraventricular haemorrhage.

\section{TABLE V}

LESIONS ASCERTAINED FROM LUNG HISTOLOGY (CASES WITH MAJOR CONGENITAL MALFORMATIONS, RHESUS ISOIMMUNIZATION, CBT AND IVH OMITTED)

\begin{tabular}{|c|c|c|c|c|c|}
\hline \multirow{2}{*}{$\begin{array}{l}\text { Registered Cause } \\
\text { of Death }\end{array}$} & \multicolumn{5}{|c|}{ Observed Cause of Death } \\
\hline & PI & MPH & HM & As $p$ & NCF \\
\hline $\begin{array}{l}762 \text { Asphyxia and } \\
\text { atelectasis }\end{array}$ & 71 & 21 & ? & 24 & 39 \\
\hline 763 Pneumonia & 66 & 9 & 9 & 5 & 10 \\
\hline $\begin{array}{l}771 \text { Haemorrhagic } \\
\text { disease }\end{array}$ & 11 & {$\left[\begin{array}{c}21 \\
-1\end{array}\right.$} & 1 & 2 & - \\
\hline 776 Immaturity & 42 & 14 & 53 & 13 & 62 \\
\hline Remainder & 58 & 14 & 39 & 21 & 15 \\
\hline Total & 248 & 79 & 177 & 65 & 126 \\
\hline
\end{tabular}

PI = pulmonary infection

MPH = massive pulmonary haemorrhage

$\mathbf{H M}=$ hyaline membranes

As $\mathrm{p}=$ meconium aspiration

NCF $=$ no cause found apart from atelectasis
Table V shows the miscellany of codings given to the various pulmonary lesions. Note that, in this 3 table, the lesions are mutually exclusive, the order of $\stackrel{\mathbb{Q}}{\circ}$ precedence being from left to right.

As already noted (Fedrick and Butler, 1971), only? a very small proportion of deaths with pulmonary을 infection are coded as pneumonia. Similarly, only a $\underline{\underline{\underline{\sigma}}}$ small fraction of the cases of massive pulmonary? haemorrhage are coded as haemorrhagic disease. $\unrhd$ Because the codes for asphyxia are the same as those for atelectasis $(762 \cdot 0,762 \cdot 5)$, it is not surprising $\overrightarrow{-}$ that the cases of hyaline membranes are more likely:to be coded in this way than are those of pure $\vec{\omega}$ asphyxia. In these cases, even were an improved set? of coding criteria available in 1958, little improve- $\stackrel{\odot}{\Omega}$ ment would have been made. For example, only on 8 of the 182 death certificates of the pneumonia cases not coded as such was mention made of this ${ }_{-}^{N}$

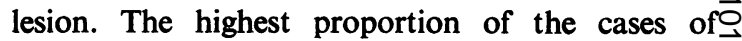
pulmonary infection that could have been coded aso such would therefore be $74 / 248(30 \%)$.

\section{Discussion}

In a study of adult death certificates of $1,216 \overrightarrow{0}$ patients who died in hospital in 1962, Alderson a fidN Meade (1967) showed that there were wide dische pancies between the principal condition treated $\bar{q}$ hospital and the underlying cause of death as stated on the death certificate, and that the discrepancy was least when a malignant neoplasm was present $\bar{\varnothing}$ and greatest for pneumonia.

The faults were not wholly due to the coding $\overrightarrow{\vec{B}}$ system employed at that time. Even with perfect ${ }^{\Im}$ coding, one is dependent on the quality of the doctor's statement as to the cause of death.

As it stood in 1958, the system of coding causes of neonatal deaths had many drawbacks. It was most? accurate in cases of anencephalus $(89 \%)$ and 3 Rhesus isoimmunization $(89 \%)$ and completelyo unable to cope with pulmonary lesions, including pneumonia. Even in such readily identifiable disorders as spina bifida, the error in coding was large, and for malformations such as diaphragmatic hernia there was only $42 \%$ accuracy.

Perhaps one of the most important findings of the present study is the poor quality of some GRO statistics for congenital malformations. This is disturbing because for some time much attention has $\omega$ been paid to fluctuations in incidence with season, year, and region of such conditions as anencephalus and spina bifida using national data (Rogers and Morris, 1971; Howe, 1970; and many others). Weatherall (1969) has already indicated that some regions report their cases of anencephalus more accurately than others, and one has the suspicion $\frac{\widetilde{Q}}{\mathbb{Q}}$ 
that variations with time may reflect variation in the trouble taken by the doctors concerned to record causes of death accurately on the death certificate.

\section{SUMmaRY}

The causes of death of 1,656 neonatal deaths occurring in England, Scotland, and Wales during March, April, and May 1958 studied by the British Perinatal Mortality Survey were compared with the underlying cause of death as coded by the respective offices of the Registrars General and with the causes of death as recorded on the death certificate.

In no cause of death category were the cases coded by the GRO identical with those ascertained by the Perinatal Mortality Survey. The greatest accuracy was obtained for cases of anencephalus and Rhesus isoimmunization ( $89 \%$ ) and the lowest was for major renal malformations and pulmonary lesions, including pneumonia. Faults were shown to lie with the coding system and especially with the quality of the statement made by the doctor on the death certificate.

We are grateful to the Executive Committee of the National Birthday Trust Fund for permission to use the data of the 1958 British Perinatal Mortality Survey, and to the Office of Population Censuses and Surveys for useful suggestions.

\section{REFERENCES}

Alderson, M. R., and Meade, T. W. (1967). Accuracy of diagnosis on death certificates compared with that in hospital records. Brit. J. prev. soc. Med., 21, 22.

Butler, N. R., and Alberman, E. D. (1969). Perinatal Problems: The Second Report of the 1958 British Perinatal Mortality Survey. Livingstone, Edinburgh.

- and BonhaM, D. G. (1963). Perinatal Mortality: The First Report of the 1958 British Perinatal Mortality Survey. Livingstone, Edinburgh.

FEDRICK, J., and ButLER, N. R. (1970). Certain causes of neonatal death: II. Intraventricular haemorrhage. Biol. Neonat. (Basel), 15, 257.

- and - (1971). Certain causes of neonatal death: III. Pulmonary infection (a) clinical factors. Biol. Neonat. (Basel), 17, 458.

Howe, G. M. (1970). National Atlas of Disease Mortality in the United Kingdom, revised edition. Nelson, London.

ROGERS, S. C., and MoRRIS, M. (1971). Infant mortality from spina bifida, congenital hydrocephalus, monstrosity and congenital diseases of the cardiovascular system in England and Wates. Ann. hum. Genet., 34, 295.

Weatherall, J. A. C. (1969). An assessment of the efficiency of notification of congenital malformations. Med. Offr, 121, 65. 